\title{
Subclinical Hypothyroidism in Children Can Normalize after Changes in Dietary Intake
}

\author{
Marjolein W. J. Kuiper, Ellen J. van der Gaag
}

Department of Pediatrics, Ziekenhuisgroep Twente, Hengelo, The Netherlands.

Email: e.gaagvander@zgt.nl

Received November $16^{\text {th }}, 2011$; revised January $15^{\text {th }}, 2012$; accepted January $23^{\text {rd }}, 2012$

\begin{abstract}
Background: There is no effective treatment for children with subclinical hypothyroidism. The natural course of subclinical hypothyroidism shows a normalization rate of $41 \%$ for Thyroid Stimulating Hormone (TSH). Objective: The thyroid needs (among others) iron, iodine, and vitamin A for a proper thyroid hormone synthesis. We hypothesize that with a dietary change, more children can normalize their TSH. Design: In this case-control study, 54 children aged 1 14 years with subclinical hypothyroidism were divided into a diet group and a control group. The diet consisted of green vegetables, beef, full fat milk, and butter. The diet was followed for at least 3 months. A total of 27 patients comprised the diet group and 27 the control group. TSH, Free T4 (FT4), and Body Mass Index (BMI) were evaluated during the follow up. Results: By following this diet, TSH levels decreased significantly compared to when following the natural course. FT4 levels did not change during the follow up. The diet group realized a change of normalizing their TSH with a RR 2.8 (95\% CI 1.45 - 5.61). There were no changes in BMI after following the diet. Conclusions: Even though our study population was small, we observed the association of a dietary change and normalization of TSH in children with subclinical hypothyroidism, without adverse effects.
\end{abstract}

Keywords: Subclinical Hypothyroidism; TSH, BMI; Vitamin A; Dairy Products; Beef; Vegetables

\section{Introduction}

Subclinical hypothyroidism (SH) in children and adults doesn't have any therapeutic options available. Should this be an issue of concern or does this not have any clinical impact? Some specialists consider it a benign normal variation and thyroid hormone can be supplemented to lower TSH. The actual cause of an increased TSH however is not known. A supplement of thyroid hormone does correct the actual TSH level, but not the origin. Recent studies show higher mortality rates in young adults (18 - 49 years of age) of coronary heart disease caused by subclinical hypothyroidism and high Thyroid Stimulating Hormone (TSH) levels [1,2]. This emphasizes the view that subclinical hypothyroidism in children isn't just harmless. A few studies have investigated the natural course of subclinical hypothyroidism [3-5]. After a 2-year follow-up, the natural course of idiopathic subclinical hypothyroidism in children showed a normalized TSH level in $41 \%$ of the patients, $12 \%$ had a progression to clinical hypothyroidism and in the other patients subclinical hypothyroidism persisted $[4,5]$. The only therapeutic intervention currently used is treatment with levothyroxine [6]. This is indicated by a TSH-value of $>10 \mathrm{mU} / \mathrm{l}$. This implicates that there is no good treat- ment for patients who have a TSH value range from 4.2 and $10 \mathrm{mU} / \mathrm{l}$. The patients are faced with waiting for the natural course.

The most common cause of subclinical hypothyroidism in children is autoimmune thyroiditis. This is diagnosed by an increased serum concentration of anti-thyroid peroxidase. Furthermore, there are a lot of other but less common causes of subclinical hypothyroidism e.g. iatrogenic disease, iodine deficiency, or excess and certain drug effects [7-12].

Several studies have been carried out examining the influence of specific nutrients on the thyroid, for example iron, iodine, and vitamin A [13-15]. These studies show that good iron, iodine, and vitamin A status are necessary for proper thyroid function.

Iron deficiency has multiple adverse effects on thyroid metabolism. It decreases amongst others the circulation of thyroid hormone. The most likely cause is through impairment of the heme-dependent thyroid peroxidase enzyme [16,17]. Vitamin A deficiency has multiple effects on thyroid function in animals; it decreases thyroidal iodine uptake and iodine incorporation into thyroglobulin, and increases thyroid size [18]. The vitamin A status also modulates TSH production by influencing 
the expression of pituitary TSHßmRNA $[19,20]$. Iodine is an essential element for adequate thyroid hormone production [21]. Chronic iodine deficiency increases the TSH concentration and produces a thyroid hormone pattern consistent with subclinical hypothyroidism [21,22].

As the most common cause of subclinical hypothyroidism is an autoimmune thyroid disease, we hypothesize that the main problem for subclinical hypothyroidism in children is an immunological dysfunction or subtle deficiencies of micronutrients, which causes disturbed thyroid hormone production. Therefore, we prepared a diet with a high nutrient density, necessary for a good thyroid function and a proper immune function. In this preliminary study, we investigated whether a diet could normalize the TSH levels of children with subclinical hypothyroidism.

\section{Methods}

\subsection{Study Population}

For this case-control study we included pediatric patients aged 1 to 14 years in this hospital from 2008 until 2011. The patients had an elevated TSH ( $>4.2 \mathrm{mU} / \mathrm{l})[23]$ and Free T4 (FT4) within the normal range $(10-25 \mathrm{pmol} / \mathrm{l})$.

The patients were assigned to the pediatricians working in a general pediatric outpatient clinic of a general hospital (Ziekenhuisgroep Twente, Hengelo, The Netherlands). One pediatrician followed the diet group for at least 3 months. The control group without dietary advices was created by patients from the other pediatricians in the same hospital.

We excluded patients with the following characteristics: clinical hypothyroidism (FT4 $<10$ pmol/l), patients treated with levothyroxine, and patients with Down's syndrome.

\subsection{Measurements}

We collected the following data: gender, age at presentation, use of medication BMI, FT4, TSH. This data was recorded before and after the study period.

TSH was measured with electro-chemiluminescence sandwich immunoassay on a COBAS 6000 (Roche Diagnostics).

\subsection{Intervention}

The intervention was a diet comprising the eating of beef 3 times a week, eating green vegetables 5 times a week, and a daily portion of full fat milk and butter. All the other dietary habits remained unchanged. Parents were advised to follow it for at least 3 months. These foods were chosen because they are rich in the most important nutrients for thyroid: iron, vitamin $\mathrm{A}$, and, to a lesser extent, iodine [13-15,24]. Table 1 shows the nutrients of
Table 1. Nutrients in the diet compared with other food [24].

\begin{tabular}{|c|c|c|c|}
\hline \multirow[t]{2}{*}{ Food } & \multicolumn{3}{|c|}{ Nutrients per 100 grams } \\
\hline & Fe total $(\mathrm{mg})$ & Iodine (ug) & Vitamin A (ug) \\
\hline Green vegetables: & & & \\
\hline Spinach boiled & 1.3 & 2.0 & 462.0 \\
\hline Broccoli boiled & 1.0 & 2.0 & 329.0 \\
\hline White vegetables: & & & \\
\hline Cauliflower boiled & 0.3 & 0.8 & 0.0 \\
\hline Chicory boiled & 0.2 & 0.4 & 2.0 \\
\hline $\begin{array}{l}\text { Beef }>10 \% \text { fat } \\
\text { prepared }\end{array}$ & 2.6 & 16.5 & 20.0 \\
\hline Chicken fillet prepared & 0.7 & 8.0 & 18.0 \\
\hline Pork prepared & 1.7 & 4.5 & 9.0 \\
\hline Butter salted & 0.1 & - & 903.0 \\
\hline Low-fat margarine & - & - & 768.0 \\
\hline Whole milk & 0.0 & 1.9 & 36.0 \\
\hline Skimmed milk & 0.0 & 2.0 & 1.0 \\
\hline $\begin{array}{l}\text { Recommended Daily } \\
\text { Allowance (children } \\
5-12 \text { years }[25,26] \text { ) }\end{array}$ & $\begin{array}{l}\text { o } 7.0-8.0 \\
\text { o } 7.0-8.0\end{array}$ & $\begin{array}{l}\text { o } 120 \\
\text { \& } 120\end{array}$ & $\begin{array}{l}5500-1000 \\
+500-800\end{array}$ \\
\hline
\end{tabular}

Vitamin A is shown in retinol equivalents $(\mu \mathrm{g})$.

the diet versus other food types. We chose a diet with multiple ingredients instead of one or two supplements because we wanted to study the influence of nutrition and its clinical impact.

\subsection{Statistical Analysis}

For the statistical analysis we used the following tests: Student's $t$-test to evaluate the differences in continuous variables and normal distribution (e.g. age, TSH, and FT4 levels) between the diet and control group. ANCOVA analysis of covariance was used for follow up of the BMI in time to correct for missing and baseline values. Pearson Chi-Square test was used for the evaluation of the normalization rate of TSH levels. Statistical analysis was performed with SPSS version 15.0 (SPSS Inc, Chicago, USA).

\subsection{Ethical Committee}

The National CCMO (Central Committee on Research Involving Human Subjects) read the protocol and found that the diet comprised ordinary food ingredients and did not suggest any major change in the lifestyle for the parents and children. They concluded that the study need not be reviewed by them.

\section{Results}

\subsection{Descriptives}

A group of 64 patients were evaluated for subclinical hypothyroidism. Of them, 7 were excluded because of 
Down's syndrome and 3 used levothyroxine. These 3 patients were given levothyroxine because of panhypopituarisme (1 patient) and clinical problems (2 patients). A total of 54 patients were included in the study. The group consisted of 15 boys and 12 girls in the diet group and 12 boys and 15 girls in the control group. The characteristics of these groups are described in Table 2. There were no ethnic differences. The diet and control group were comparable with respect to TSH start, FT4, age and BMI. The follow-up period took a little more than 3 months in both groups.

\subsection{Intervention}

Student's $t$-test showed that TSH at the end evaluation between diet and control group did change significantly $(p<0.000)$. The percentage of patients with normalized TSH $(\mathrm{TSH} \leq 4.2 \mathrm{mU} / \mathrm{l})$ was $74.1 \%$ in the diet group compared to $25.9 \%$ in the control group $(p<0.000)$. The relative risk to normalized TSH with the diet was 2.8 (95\% CI 1.45 - 5.61).

The diet group followed the diet for 3 months and after that period they were allowed to choose if they wanted to follow it or not. Most of the patients continued eating the components but less than the advised amounts.

\subsection{Growth Aspects}

We measured the BMI during the 3 months of the diet because we wanted to investigate if the children gained more weight after they ingested more full-fat dairy products. Their weight increased slightly but height also increased. In the diet group, BMI values did not change

Table 2. Descriptives and comparisons between the diet and control groups at presentation and after following the diet for 3 months.

\begin{tabular}{cccc}
\hline & $\begin{array}{c}\text { Diet Group } \\
N=27\end{array}$ & $\begin{array}{c}\text { Control Group } \\
N=27\end{array}$ & $\begin{array}{c}95 \% \text { CI of } \\
\text { the difference }\end{array}$ \\
\hline Age (years) (SE) & 5.1 & 6.6 & $(-3.3-0.43)$ \\
& $(0.70)$ & $(0.62)$ & $\mathrm{p}=0.129$ \\
TSH start (mU/l) (SE) & 5.7 & 5.5 & $(-0.30-0.85)$ \\
& $(0.21)$ & $(0.19)$ & $\mathrm{p}=0.352$ \\
TSH end (mU/l) (SE) & 3.5 & 4.9 & $(0.84-2.4)$ \\
& $(0.28)$ & $(0.27)$ & $\mathrm{p}<0.000$ \\
FT4 start (SE) & 16.6 & 15.6 & $(-0.12-2.0)$ \\
& $(0.41)$ & $(0.34)$ & $\mathrm{p}=0.80$ \\
FT4 end (SE) & 16.1 & 15.4 & $(-0.55-1.1)$ \\
Follow up & $(0.33)$ & $(0.26)$ & $\mathrm{p}=0.48$ \\
(months) (SE) & 3.8 & 3.5 & $(-0.49-1.0)$ \\
BMI start* (SE) & $(0.26)$ & $(0.26)$ & $\mathrm{p}=0.494$ \\
& 16.5 & 17.4 & $(-2.5-0.64)$ \\
BMI end* (SE) & $(0.35)$ & $(0.69)$ & $\mathrm{p}=0.234$ \\
& 16.5 & 17.9 & $(0.01-1.1)$ \\
& $(0.14)$ & $(0.23)$ & $\mathrm{p}=0.045$ \\
\hline
\end{tabular}

Tested with Student t-test, equal variances assumed except for * Pearson Chi-Square test. Standard Error of the mean (SE) between bars. after 3 months of following the diet. Before the diet, the mean BMI was 16.47. After 3.8 months the mean BMI was 16.49. The control group started with a higher BMI and this increased during the study period. After the study period there was a significant difference in BMI values between the two groups. This difference wasn't present at the start.

\section{Discussion}

We investigated the relation between the dietary intake of nutrients necessary for a proper thyroid function and the effect on subclinical hypothyroidism. When children followed the diet, their TSH levels decreased significantly after only 3.8 months. Wasniewska and De Luca et al. followed the natural course of subclinical hypothyroidism. They concluded that TSH normalized in $41 \%$ of the child patients $[4,5]$. Our control group showed a normalization rate close to their numbers $(25.9 \%)$, but the follow-up period was much shorter (several months compared to 2 years). In the diet group $74 \%$ of the patients showed normalized TSH. This strongly indicates that there is a difference in following the diet or awaiting the natural course. This implicates that subclinical hypothyroidism may have a nutritional component in the pediatric age group. A dietary change can be a simple and cost-effective method to avoid long term treatment with thyroid medication, which diminishes significant expenses for doctor's visits, lab monitoring and medication costs.

In developed countries, dietary sources of iodine are mainly bread, milk, and use of iodized salt [27,28]. As bread is eaten by almost all children (data not shown), we did focus on other food groups in our diet. As our diet did not contain large amounts of iodine, this could not explain the shifts in thyroid function. Vitamin A and iron are present in larger amounts in our diet and therefore contribute more to the stimulation of the thyroid. Not only a single component, but also the interaction between all the components was found to improve thyroid function. In children who are both deficient for vitamin $\mathrm{A}$ and iodine, the supplementation of vitamin A was observed to improve the efficacy of iodine uptake [13]. In addition, vitamin A supplements was also found to improve thyroid function without a change in iodine nutrition [22].

Beside the nutrients for a good thyroid function, the diet also contains nutrients necessary for a proper immunological status [29]. Vitamin A is important for the immune function and protection against infections [30]. Most of the negative effects of vitamin A deficiency on host defense appear to be reversible with restoration of vitamin A status [31]. Iron deficiency is associated worldwide with an increased incidence of infections [31]. The molecular and cellular mechanisms responsible for immune changes during iron deficiency are complex and 
remain unclear. This is because iron is important in several crucial, metabolic pathways in immune cells [29]. In general, iron does regulate the function of $\mathrm{T}$ lymphocytes, but immune cells differ from each other in their use of iron-binding proteins and various immune functions experience differential effects of the iron status [32]. It is already known that the most common cause for subclinical hypothyroidism is an autoimmune disease [12]. As this is an immunological disorder, an underlying disturbance of the immune system is suspected. As our diet has several components that modulate the immune system this might explain why our diet contributes to a more stable thyroid function.

The limitations of our study are the small number of patients involved and the study design, this being a non randomized case-control study. Since they were not randomly assigned to the diet or control group, a bias for the dietary group could be introduced. The control group was selected from our hospital by using charts of pediatricians. They did not evaluate the food pattern of the control group and therefore we have no evidence if their intake could be compared to the study group. Secondly, TSH levels tend to increase when weight/BMI and age increases. Our control group had higher BMI levels at the end. This was also the case with their TSH levels. This tendency however was not seen at presentation when the TSH levels of the diet group were relatively high in relation to their BMI. The age factor was also not consequent. BMI in the dietary group did not increase during the study period but did increase in the control group in the same study period.

Future studies also need to pay attention to the weight of the children. The diet consists of saturated fat and high calories caused by the full-fat milk and butter. On the other hand it contains a combination of high and low energy density food with a relatively high nutrient density. We found that the BMI in our study population did not change. It is important to closely monitor this. Parents mentioned that their children ingested less snacks because they experienced a feeling of satiety during the diet. Looking at the risk of coronary heart disease by subclinical hypothyroidism, the effects of the saturated fats in the children's future life are also a subject of discussion. Nowadays, the advice that eating saturated fat can kill a person through coronary heart disease has not been confirmed by all studies [33-35]. The intake of 0.5 liter milk daily has been proven to have no negative health effects. On the contrary natural milk fat components have important roles in the body [36] and can protect against a high waist circumference, elevated blood pressure, low HDL levels and high fasting insulin levels [37-39]. These remarks do not count for the increasing consumption of milk products with added sugar. Health benefits of these artificially flavored dairy products should be questioned [36].

A strong aspect of our study is that it concerns an intervention without any adverse effects. The dietary changes consist of everyday food which are available for all social classes. Parents can implement the dietary change into their daily routine and it can become easier after due time.

The variability can also be mentioned as a critical remark because of inconsistencies in the dietary intake. There are multiple variables about the food intake of the children. Do parents cook fresh or frozen vegetables? Do the children eat 1 or 4 spoons of vegetables or meat? When the children are ill is it logical that the dietary intake decreases and should we correct for that? Spinach contains more micronutrients when compared with lettuce and they are both green vegetables. All these critical remarks are true and can be observed in our study. Our goal was to study the influence of natural and non-artificial, non-fortified food on subclinical hypothyroidism. During the investigation of the influence of the supplementation of different micronutrients alone, these variables should be eliminated. However, we wanted to study the effect in realistic everyday life. People do not eat the same vegetables or ingredients every day and may want some variation. With our diet they can choose between a lot of different vegetables and different ways to prepare the meat. We found that our dietary advice made the parents more aware of the benefits of food and that they chose the food for their children more prudentially.

\section{Conclusion}

We have shown that following our diet for 3 months TSH levels decrease significantly. This implicates a possible nutritional component for subclinical hypothyroidism in the pediatric age group. Possible ways of the nutritional benefits are supplementation of (subclinical) micronutrient deficiencies or an immunomodulating effect by different components of the diet. It is important to underline that our diet is not an intensive treatment. The diet consists of ordinary, everyday natural food that is available to everyone and has no side effects. Therefore, as there is still no good alternative therapy, we can advise our diet as a cost-effective treatment for children with subclinical hypothyroidism.

\section{Acknowledgements}

EvdG thanks her co-researchers/friends who helped to translate daily practice into scientific research.

\section{REFERENCES}

[1] N. Rodondi, W. P. den Elzen, D. C. Bauer, A. R. Cappola, S. Razvi, J. P. Walsh, B. O. Asvold, G. Iervasi, M. Imai- 
zumi, T. H. Collet, A. Bremner, P. Maisonneuve, J. A. Sgarbi, K. T. Khaw, M. P. Vanderpump, A. B. Newman, J. Cornuz, J. A. Franklyn, R. G. Westendorp, E. Vittinghoff and J. Gussekloo, "Subclinical Hypothyroidism and the Risk of Coronary Heart Disease and Mortality," Journal of the American Medical Association (JAMA), Vol. 304, No. 12, 2010, pp. 1365-1374.

doi:10.1001/jama.2010.1361

[2] N. Rodondi, D. Aujesky, E. Vittinghoff, J. Cornuz and D. C. Bauer, "Subclinical Hypothyroidism and the Risk of Coronary Heart Disease: A Meta-Analysis," American Journal of Medicine, Vol. 119, No. 7, 2006, pp. 541-551. doi:10.1016/i.amjmed.2005.09.028

[3] D. C. Moore, "Natural Course of 'Subclinical' Hypothyroidism in Childhood and Adolescence," Archives of Pediatrics \& Adolescent Medicine, Vol. 150, No. 3, 1996, pp. 293-297. doi:10.1001/archpedi.1996.02170280063012

[4] M. Wasniewska, M. Salerno, A. Cassio, A. Corrias, T. Aversa, G. Zirilli, D. Capalbo, M. Bal, A. Mussa and L. F. De, "Prospective Evaluation of the Natural Course of Idiopathic Subclinical Hypothyroidism in Childhood and Adolescence," European Journal of Endocrinology, Vol. 160, No. 3, 2009, pp. 417-421. doi:10.1530/EJE-08-0625

[5] F. De Luca M. Wasniewska, G. Zirilli, T. Aversaand Arrigo, "At the End of a Two-Year Follow-Up Elevated TSH Levels Normalize or Remain Unchanged in Most the Children with Subclinical Hypothyroidism," Italian Journal of Pediatrics, Vol. 36, No. 1, 2010, p. 11. doi:10.1186/1824-7288-36-11

[6] L. H. Fish, H. L. Schwartz, J. Cavanaugh, M. W. Steffes, J. P. Bantle and J. H. Oppenheimer, "Replacement Dose, Metabolism, and Bioavailability of Levothyroxine in the Treatment of Hypothyroidism. Role of Triiodothyronine in Pituitary Feedback in Humans," New England Journal of Medicine, Vol. 316, No. 13, 1987, pp. 764-770. doi:10.1056/NEJM198703263161302

[7] A. P. Weetman and A. M. McGregor, "Autoimmune Thyroid Disease: Developments in Our Understanding," Endocrine Reviews, Vol. 5, No. 2, 1984, pp. 309-355.

[8] S. Mariotti, P. Caturegli, P. Piccolo, G. Barbesino and A. Pinchera, "Antithyroid Peroxidase Autoantibodies in Thyroid Diseases," The Journal of Clinical Endocrinology \& Metabolism, Vol. 71, No. 3, 1990, pp. 661-669. doi:10.1210/jcem-71-3-661

[9] R. A. Nordyke, F. I. Gilbert Jr., L. A. Miyamoto and K. A. Fleury, "The Superiority of Antimicrosomal over Antithyroglobulin Antibodies for Detecting Hashimoto's Thyroiditis," Archives of Internal Medicine, Vol. 153, No. 7, 1993, pp. 862-865. doi:10.1001/archinte.153.7.862

[10] W. M. Tunbridge, D. C. Evered, R. Hall, D. Appleton, M. Brewis, F. Clark, J. G. Evans, E. Young, T. Bird and P. A. Smith, "The Spectrum of Thyroid Disease in a Community: The Whickham Survey," Clinical Endocrinology, Vol. 7, No. 6, 1977, pp. 481-493. doi:10.1111/j.1365-2265.1977.tb01340.x

[11] G. J. Canaris, N. R. Manowitz, G. Mayor and E. C. Ridgway, "The Colorado Thyroid Disease Prevalence
Study," Archives of Internal Medicine, Vol. 160, No. 4, 2000, pp. 526-534. doi:10.1001/archinte.160.4.526

[12] T. P. Foley Jr., V. Abbassi, K. C. Copeland and M. B. Draznin, "Brief Report: Hypothyroidism Caused by Chronic Autoimmune Thyroiditis in Very Young Infants," New England Journal of Medicine, Vol. 330, No. 7, 1994, pp. 466-468. doi:10.1056/NEJM199402173300704

[13] M. B. Zimmermann, "Interactions of Vitamin A and Iodine Deficiencies: Effects on the Pituitary-Thyroid Axis," International Journal for Vitamin and Nutrition Research, Vol. 77, No. 3, 2007, pp. 236-240. doi:10.1024/0300-9831.77.3.236

[14] M. B. Zimmermann, R. Wegmuller, C. Zeder, N. Chaouki and T. Torresani, "The Effects of Vitamin A Deficiency and Vitamin A Supplementation on Thyroid Function in Goitrous Children," The Journal of Clinical Endocrinology \& Metabolism, Vol. 89, No. 11, 2004, pp. 5441-5447. doi:10.1210/jc.2004-0862

[15] G. A. Kandhro, T. G. Kazi, H. I. Afridi, N. Kazi, M. B. Arain, R. A. Sarfraz Sirajuddin, N. Syed, J. A. Baig and A. Q. Shah, "Evaluation of Iron in Serum and Urine and Their Relation with Thyroid Function in Female Goitrous Patients," Biological Trace Element Research, Vol. 125, No. 3, 2008, pp. 203-212. doi:10.1007/s12011-008-8174-Z

[16] M. B. Zimmermann, "The Influence of Iron Status on Iodine Utilization and Thyroid Function," Annual Review of Nutrition, Vol. 26, 2006, pp. 367-389.

doi:10.1146/annurev.nutr.26.061505.111236

[17] S. Y. Hess, M. B. Zimmermann, M. Arnold, W. Langhans and R. F. Hurrell, "Iron Deficiency Anemia Reduces Thyroid Peroxidase Activity in Rats," Journal of Nutrition, Vol. 132, No. 7, 2002, pp. 1951-1955.

[18] K. Oba and S. Kimura, "Effects of Vitamin A Deficiency on Thyroid Function and serum Thyroxine Levels in the Rat," Journal of Nutritional Science and Vitaminology (Tokyo), Vol. 26, No. 4, 1980, pp. 327-334. doi: $10.3177 /$ jnsv. 26.327

[19] N. S. Brown, A. Smart, V. Sharma, M. L. Brinkmeier, L. Greenlee, S. A. Camper, D. R. Jensen, R. H. Eckel, W. Krezel, P. Chambon and B. R. Haugen, "Thyroid Hormone Resistance and Increased Metabolic Rate in the RXR-Gamma-Deficient Mouse," Journal of Clinical Investigation, Vol. 106, No. 1, 2000, pp. 73-79. doi:10.1172/JCI9422

[20] J. J. Breen, T. Matsuura, A. C. Ross and J. A. Gurr, "Regulation of Thyroid-Stimulating Hormone Beta- Subunit and Growth Hormone Messenger Ribonucleic Acid Levels in the Rat: Effect of Vitamin A Status," Endocrinology, Vol. 136, No. 2, 1995, pp. 543-549. doi:10.1210/en.136.2.543

[21] M. B. Zimmermann, "Iodine Deficiency," Endocrine Reviews, Vol. 30, No. 4, 2009, pp. 376-408. doi:10.1210/er.2009-0011

[22] M. B. Zimmermann, P. L. Jooste, N. S. Mabapa, S. Schoeman, R. Biebinger, L. F. Mushaphi and X. Mbhenyane, "Vitamin A Supplementation in Iodine-Deficient African Children Decreases Thyrotropin Stimulation of 
the Thyroid and Reduces the Goiter Rate," American Journal of Clinical Nutrition, Vol. 86, No. 4, 2007, pp. 1040-1044.

[23] T. E. Hamilton, S. Davis, L. Onstad and K. J. Kopecky, "Thyrotropin Levels in a Population with no Clinical, Autoantibody, or Ultrasonographic Evidence of Thyroid Disease: Implications for the Diagnosis of Subclinical Hypothyroidism," The Journal of Clinical Endocrinology \& Metabolism, Vol. 93, No. 4, 2008, pp. 1224-1230. doi:10.1210/jc.2006-2300

[24] The Hague: Dutch Food Center, "NEVO-Tabel 2006: Nederlands Voedingsstoffenbestand 2006," 2006.

[25] The Dutch Health Council, "Healthy Nutrition," 2010. www.gezondheidsraad.nl

[26] World Health Organization and International Council for the Control of Iodine Deficiency Disorders, “Assessment of Iodine Deficiency Disorders and Monitoring Their Elimination, a Guide for Programme Managers,” 2007.

[27] M. Haldimann, A. Alt and A. Blanc, "Iodine Content of Food Groups," Journal of Food Composition and Analysis, Vol. 18, 2005, pp. 461-471. doi:10.1016/j.jfca.2004.06.003

[28] E. N. Pearce, S. Pino, X. He, H. R. Bazrafshan, S. L. Lee and L. E. Braverman, "Sources of Dietary Iodine: Bread, Cows' Milk, and Infant Formula in the Boston Area," The Journal of Clinical Endocrinology \& Metabolism, Vol. 89, No. 7, 2004, pp. 3421-3424. doi:10.1210/jc.2003-032002

[29] C. J. Field, I. R. Johnson and P. D. Schley, "Nutrients and Their Role in Host Resistance to Infection," Journal of Leukocyte Biology, Vol. 71, No. 1, 2002, pp. 16-32.

[30] M. T. Cantorna, F. E. Nashold and C. E. Hayes, "Vitamin A Deficiency Results in a Priming Environment Conducive for Th1 Cell Development," European Journal of Immunology, Vol. 25, No. 6, 1995, pp. 1673-1679. doi:10.1002/eji.1830250629

[31] S. S. Twining, D. P. Schulte, P. M. Wilson, B. L. Fish and J. E. Moulder, "Vitamin A Deficiency Alters Rat Neutrophil Function," Journal of Nutrition, Vol. 127, No. 4, 1997 , pp. 558-565.
[32] J. D. Kemp, "The Role of Iron and Iron Binding Proteins in Lymphocyte Physiology and Pathology," Journal of Clinical Immunology, Vol. 13, No. 2, 1993, pp. 81-92. doi:10.1007/BF00919264

[33] F. B. Hu, J. E. Manson and W. C. Willett, "Types of Dietary Fat and Risk of Coronary Heart Disease: A Critical Review," Journal of the American College of Nutrition, Vol. 20, No. 1, 2001, pp. 5-19.

[34] K. Oh, F. B. Hu, J. E. Manson, M. J. Stampfer and W. C. Willett, "Dietary Fat Intake and Risk of Coronary Heart Disease in Women: 20 Years of Follow-Up of the Nurses' Health Study," American Journal of Epidemiology, Vol. 161, No. 7, 2005, pp. 672-679. doi:10.1093/aje/kwi085

[35] B. Lands, "A Critique of Paradoxes in Current Advice on Dietary Lipids," Progress in Lipid Research, Vol. 47, No. 2, 2008, pp. 77-106. doi:10.1016/j.plipres.2007.12.001

[36] A. Haug, A. T. Hostmark and O. M. Harstad, "Bovine Milk in Human Nutrition-A Review," Lipids Health Disease, Vol. 6, 2007, p. 25. doi:10.1186/1476-511X-6-25

[37] M. B. Snijder, A. A. van der Heijden, R. M. van Dam, C. D. Stehouwer, G. J. Hiddink, G. Nijpels, R. J. Heine, L. M. Bouter and J. M. Dekker, "Is Higher Dairy Consumption Associated with Lower Body Weight and Fewer Metabolic Disturbances? The Hoorn Study," American Journal of Clinical Nutrition, Vol. 85, No. 4, 2007, pp. 989-995.

[38] C. S. Berkey, H. R. Rockett, W. C. Willett and G. A. Colditz, "Milk, Dairy Fat, Dietary Calcium, and Weight Gain: A Longitudinal Study of Adolescents," Archives of Pediatrics \& Adolescent Medicine, Vol. 159, No. 6, 2005, pp. 543-550. doi:10.1001/archpedi.159.6.543

[39] L. M. Steffen, C. H. Kroenke, X. Yu, M. A. Pereira, M. L. Slattery, H. L. Van, M. D. Gross and D. R. Jacobs Jr., "Associations of Plant Food, Dairy Product, and Meat Intakes with 15-y Incidence of Elevated Blood Pressure in Young Black and White Adults: The Coronary Artery Risk Development in Young Adults (CARDIA) Study," American Journal of Clinical Nutrition, Vol. 82, No. 6, 2005, pp. 1169-1177. 